---مجلة علوم الرافدين، المجلد 27، العدد 4 /عدد خاص بالمؤتمر العلمي الثالث لعلوم الحياة، ص 115-128، 2018----

$$
\begin{aligned}
& \text { Aureobasidium pullulans تثخيص جزيئي لعزلات محلية من الفطر }
\end{aligned}
$$

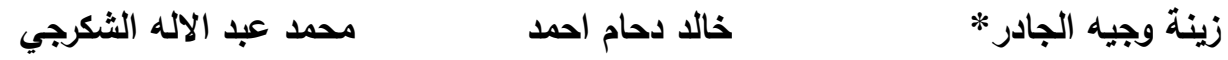

$$
\begin{aligned}
& \text { قسم علوم الحياة/ كلية التربية للعلوم الصرفة/ جامعة الموصل اهل } \\
& \text { جاسم محمد عبدو } \\
& \text { مركز بحوث دهوك/ كلية الطب البيطري/ جامعة دهوك }
\end{aligned}
$$

*E-mail: Zena.algader@yahoo.com

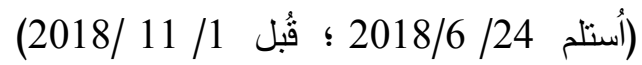

\title{
الملخص
}

تم عزل عشرين عزلة فطرية محلية من جنس Aureobasidium من اوراق سليمة لأثجار الحمضيات المختلفة.

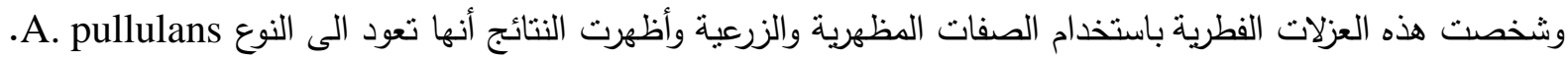

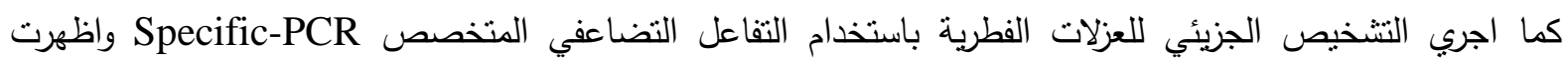
النتائج 17 حزمة من الـDNA الجينومي المنقى من العزلات الفطرية المحلية بحجم واحد ينراوح مابين (500-600) زوج قاعدة.

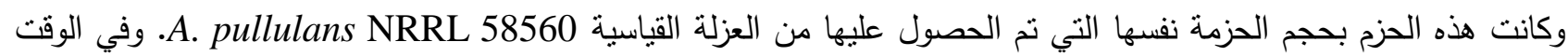
نفسه لم تظهر اية حزمة من الـDNA نتيجة تفاعل الـ Specific- PCR الخاصة بالعزلات (Ap15 و Ap17 و Ap18) في هلام

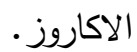

وحدد تسلسل القواعد النايتروجينية لنواتج التفاعل التضاعفي المتخصص specific PCR بعينات الـ DNA الـ الماخوذة من ثلاث عزلات محلية منتخبة واظهرت نتائج التحليل باستخدام برنامج DNA Blast/NCBI وجود نشابه اكثر من 95\% بين تسلسلات العزلات المحلية وتسلسلات السلالة القياسية A. pullulans المسجلة في بنك الجينات. كما رصدت الدراسة وجود طفرات نقطية ضمت طفرات استبدال او اضافة او حذف بعض القواعد النايتروجينية في بعض المواقع عند مقارنة التسلسلات العائدة للعزلات المحلية وتلك القياسية، وهذه الطفرات قد حدثت تلقائيا. ارسلت نتائج التحليل هذه الى بنك الجينات باستخدام الموقع الالكتروني في الـ NCBI وأدخلت في بنك الجينات كعزلة Ap7.sqn ،Ap1.sqn Ap1 KX964610 قياسية واعطيت رقماً ورمزاً خاصاً بها في بنك الجينات على النحو الاتي Ap14.sqn Ap14 KX964612 Ap7: KX964611 وصحة تشخيص العزلات المحلية قيد الدراسة.

الكلمات الدالة: Aureobasidium pullulans، NCBI، Sequencing،

\section{Molecular Identification of the Local Isolated Fungi Aureobasidium pullulans}

\section{Zena W. Al-gader \\ Khalid D. Ahmed \\ Mohammed A. Al-shakarchi}

Department of Biology/College of Education Pure Science/ University of Mosul Jasem M. Abdo

College of Veterinary Medicine/ University of Duhok 


\begin{abstract}
Twenty fungal isolates of Aureobasidium were isolated from many healthy leaves of different citrus trees. Fungal isolates understudy were identified by using morphological and cultural characters. The results revealed that the isolates are belonged to the species $A$.pullulans. Molecular identification of the isolated fungi were carried out using the specific-PCR reaction. The results showed 17 bands of purified genomic DNA from local fungal isolates of similar size ranging (500-600)bp. These bands have the same size to that obtained from the standard strain A. pullulans NRRL 58560. On the other hand, it did not show any band of the DNA as a result of the SpecificPCR reaction specialize of isolates (Ap15 and Ap17 and Ap18) in the agarose gel.

The sequence of the nitrogenous bases for the Specific PCR products were determined for three chosen local isolates. The results were analyzed using DNA Blast / NCBI program revealed that there is a similarity higher than $95 \%$ between these sequences and those of the standard strains of A. pullulans already recorded in the Gene Bank. Additionally, the point mutations whether they are substitution or addition or deletion were observed in some positions of the nitrogenous bases after comparing the sequences of the tested local isolates and the standard. These mutations may occur spontaneously.

This analysis results sent to GenBank using the website of the NCBI and introduced in GenBank record as standard isolates and given a cod number in the GenBank as follows: Ap1.sqn Ap1 KX964610, Ap7.sqn Ap7: KX964611, Ap14.sqn Ap14 KX964612 This confirms the validity of the results obtained in this study and diagnosis of the validity of the local isolates under study.
\end{abstract}

Keywords: Aureobasidium pullulans, NCBI, sequencing, Specific PCR.

\title{
المقدمة
}

يعد الفطر Aureobasidium pullulans احد اهم الفطريات المنتجة للسكريات المتعددة المهمة صناعيا وهو البوليولان. هذا الفطر من الفطريات الرمية التغذية التي تعود الى عائلة Dothideaceae تحت رنبة Dothideales التابعة لصف خلاياها، (Yurlova and de Hoog, 1997) Ascomycetes خلاياها. وينتشر هذا الفطر بشكل واسع في البيئة اذ امكن عزله من التربة ومن بقايا النباتات والخشب والصخور وسطوح

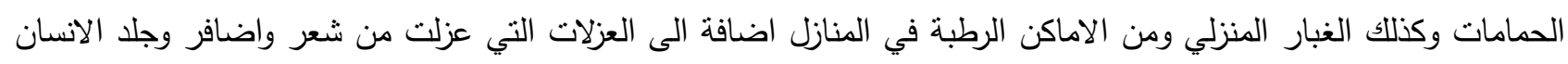

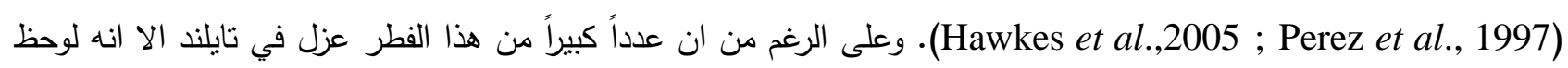
وجود مدى واسع من النباين المظهري والخصائص الفسلجية بين العزلات حيث ان معظم هذه العزلات تم عزلها من سطوح اوراق

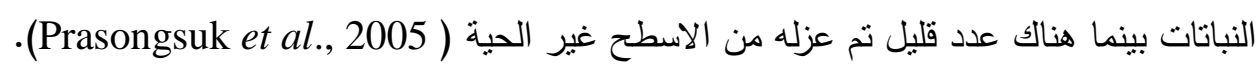

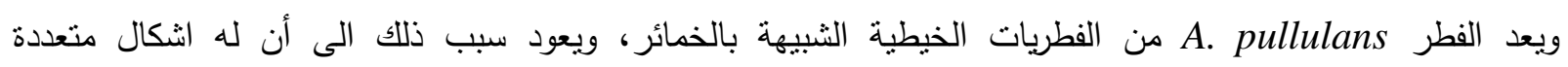

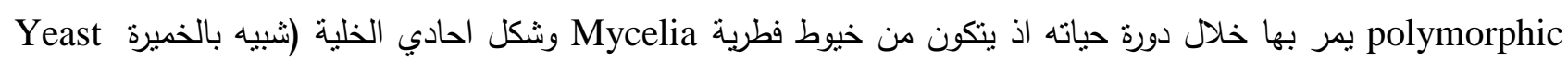

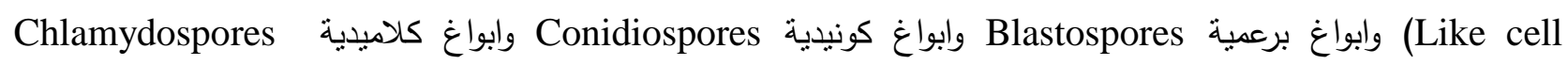
.(Punnapayak et al., 2003)

وتخزن المعلومات الوراثية Genetic Information في جزيئة الـDNA للخلية وهذه المعلومات تحدد الطبيعة التركيبية والايضية لهذا الكائن، والمحتوى الوراثي للابواغ مقسم الى قطع تسمى المورثات Genes وهي تسلسل من النيوكليوتيدات تمتلك وظائف متخصصة بعضها يشفر بناء جزيئة RNA وبروتين وتدعى بـ : مورثات تركيبية Structural Genes وبعضها الاخر له له وظائف نتظيمية في السيطرة على الفعالية الخلوية تسمى المورثات المنظمة Regulatory Genes (Paolella,1998). واظهرت Random RAPD-PCR الدراسات مدى التباين الوراثي مابين الانواع المدروسة باستخدام البصمة الوراثية عن طريق استخدام علئية 
Restriction Fragment Length وتقنية تحليل تباين اطوال قطع التقييد Polymerase Chain Reaction .(Dunber et al., 2001 ; Edwardes and Turco, 2005) (RFLP) Polymorphism مواد وطرائق العمل

عزل العزلات المحلية Isolation Local Isolates تم جمع العزلات من اوراق غير مصابة لنبانات مختلفة حسب طريقة Pollock (1992) باستخدام الوسط السائل المتكون من مما يأتي ( غم/لتز من الماء المقطر ): 10غم من السكروز و 1غم من 10 و 0.02 غم لكل من $\mathrm{K}_{2} \mathrm{HPO}_{4}$ ضغط 1 جو ودرجة حرارة 121 مُ ولمدة 15 دقيقة. تحضير اللقاح تم تحضير اللقاح حسب طريقة Ono (1977) ويتكون وسط اللقاح من المكونات الاتية (غم/لتر): 50 غم من الكلوكوز و 5 غم من extract دقيقة. عزل وتنقية الـDNA الجينومي:

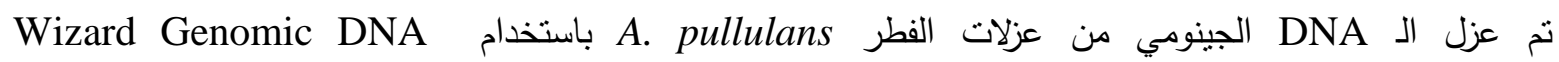

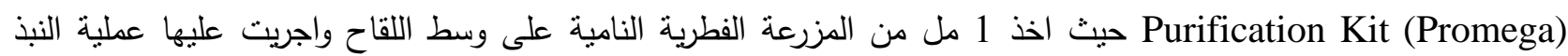
المركزي بسرعة 13000 دورة \دقيقة ولمدة 2 دقيقة وبدرجة حرارة 4 م. وسكب الراشح وعلق الراسب الفطري بـ293 مايكروليتز من محلول EDTA mM 50 وبعد المزج اجريت عليها عملية النبذ المركزي كما في الخطوة السابقة، وسكب الراشح وعلق الراسب الفطري بمانس مايكروليتز من محلول Nuclei Lysis وبعد المزج اجري على الطريقة بعض التحوير باستخدام طريقة

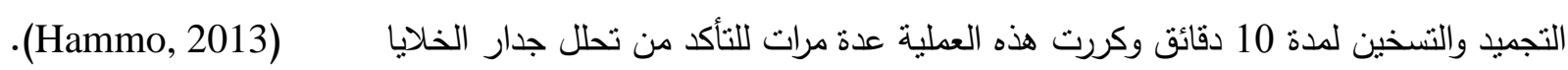
وأضيف 100 مايكروليتز من محلول ترسيب البروتين (Protein Precipitation Solution) إلى المزيج وبعد تحريكه حضن بحمام ثلجي لمدة خمس دقائق أعقبته عملية النبذ المركزي بسرعة 13000 دورة /دقيقة ولمدة 3 دقائق وبدرجة حرارة 4 مُ م. ثم نقل الراشتح إلى أنبوبة نظيفة ومعقمة يضم 300 مايكروليتز من كحول الايزوبروبانول بدرجة حرارة المختبر وتم تحريك المزيج بقلب الانبوب الى الاعلى والاسفل، وأجريت عملية النبذ المركزي وبالظروف المذكورة انفا. سكب الراشتح وغسلت الخلايا بـ 300

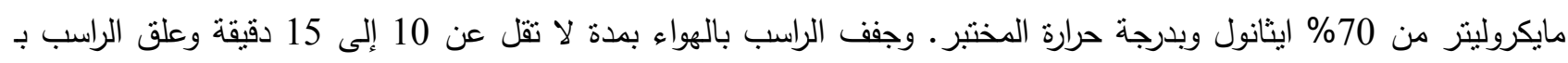
50 مايكروليتر من محلول Rehydration solution) DNA Rehydration) ثم اضيف الى المزيج 1.5 مايكروليتر من انزيم RNase وحضن بدرجة حرارة 37 مُ لمدة 15 دقيقة بعدها حفظ بدرجة حرارة 4 م لحين الاستخدام.

Specific PCR التفاعل المتسلسل المتبلمر التخصصن بدرة تم إجراء هذا التفاعل في مركز دهوك للبحوث Duhok Research Center (DRC) / كلية الطب البيطري/ جامعة دهوك باستخدام البرايمرات التخصصية IST5 forward

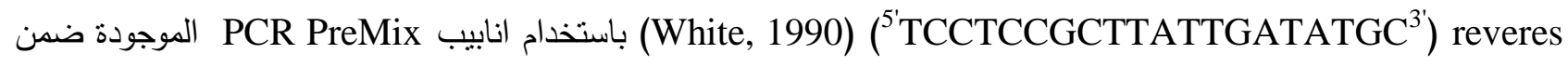
(Bioneer)Kit). وكل أنبوب تفاعل أضيف له 10 بيكومول من كل من البرايمرات و 100 نانوغرام من الـ DNA واكمل الحجم 
Eppendrof ) Thermocycler الى 20 مايكروليتز بالماء المقطر المعق. ووضعت الأنابيب في جهاز المبلمر الحراري الأ: مastercycler /Germany

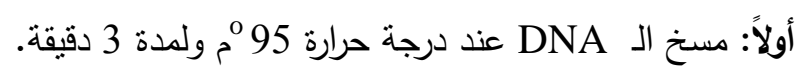
ثانياً: 34 دورة وتتضمن:

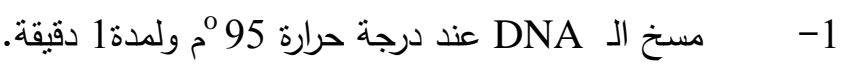

-2 - ارتباط البادئات بقطعة DNA عند درجة حرارة 58 م ولمدة 1 دقيقة.

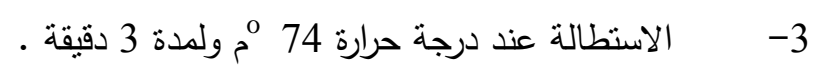

ثالثاً: مرحلة الاستطالة النهائية 74 o م ولمدة 10 دقائق.

بعد انتهاء فترة البرنامج رحلت العينات على هلام الاكاروز بتركيز 1.5 \% ولمدة 45 دقيقة تحت فرق جهد 120 فولت وكثف عن نتائج التفاعلات باستخدام جهاز Vilber Lourmat ) visualized ultra-violet (UV) Transillumination

.(Made In Ess

تعيين تسلسل القواعد النيتروجينية لنواتج التفاعل التضاعفي المتخصص لـ Specific PCR

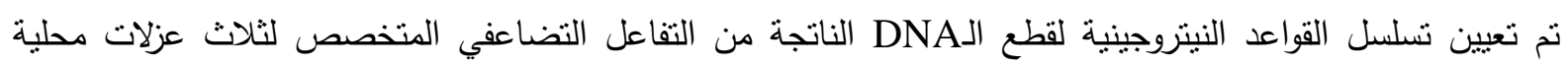

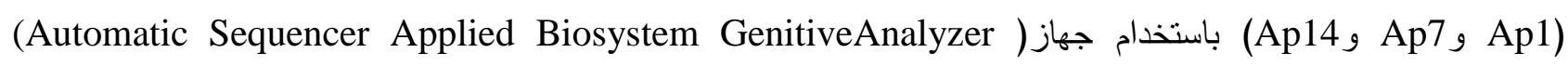
Big Dye ${ }^{\circledR}$ Terminator V3.1 Cycle Sequencing Kit, Applied Biosystem, USA) وبواسطة 3130,USA) في مركز الجينوم/ كلية العلوم والصحة/ جامعة كوبا/ اقليم كوردستان/ العراق •

تحليل تسلسل القواعد النتروجينية لنواتج التفاعل التضاعفي المتخصص Specific PCR وتعيين المخطط الثجيري

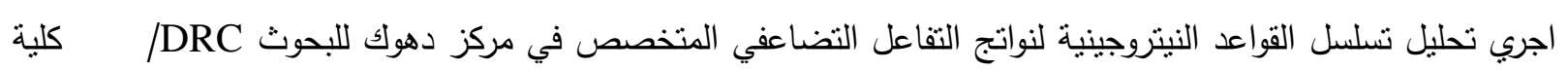
الطب البيطري/ جامعة دهوك باستخدام برنامج DNASTAR/Laser Gene وتم تجميع التسلسلات لكل عينة كلا على حدة في .SeqMan (DNASTAR/Laser gene, Madison, WI) وحررت جميع التسلسلات باستخدام المعاينة البصرية. ثم أدخلت نسلسلات العينات في برنامج NCBI BLAST الذي يرسلها الى ابحاث الجينوم في بنك الجينات عن طريق باست

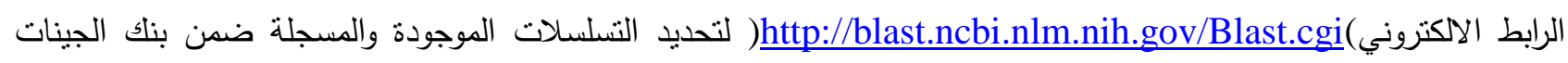
والمشابهة للتسلسلات قيد الدراسة.

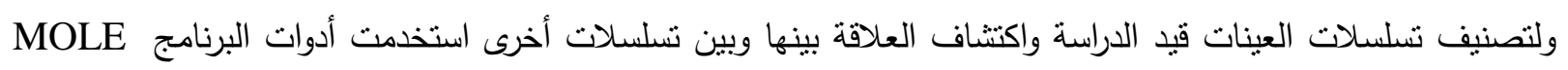
BLAST العلاقة التصنيفية عن طريق الرابط الاكتروني: (http://blast.ncbi.nlm.nih.gov/moleblast/moleblast.cgi)

\section{النتائج والمناقشة}

تشخيص العزلات المحلية تم الحصول على العزلات الفطرية المحلية من مصادر عديدة واوراق نباتات مختلفة وشخصت بشكل مبدئي بالاعتماد على الثكل الخارجي Morphology للمستعمرات، فقد كانت المستعمرات ذات الوان متباينة مابين (الاسود والوردي والكريمي)

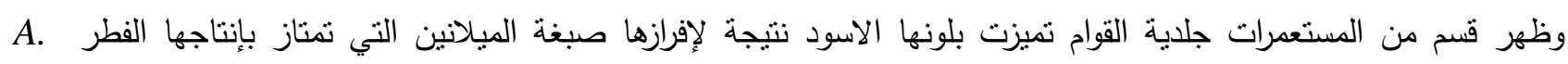
(Wu et al., 2012 ; Manitchotpisit, 2011) pullulans 
سطوحها مرتفعة ذات حافات ملساء مخاطية القوام عالية اللزوجة (الثكل، 1). ونظرا للانتشار الواسع لهذا الفطر فان عددا كبيرا من السلالات والعزلات نم عزلها من مصادر عديدة لايمكن احصاؤها وقد وردت كثير من سلالات الفطر في مختلف البحوث

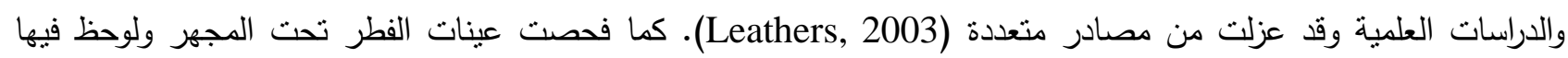
تعددية الاطوار اذ ظهر فيها الطور الخميري وحيد الخلية، والطور الخيطي متعدد الخلايا وطور الكلاميدوسبور (السبورات الكلاميدية) (الثكل،A-2) وتمت مقارنتها بالعزلة القياسية للفطر A. pullulans NRRL58560 فأظهرت نطابقاً تاماً (الثكل، وهئ (B-2) وهذا يطابق وصف (Prasongsuk et al., 2005) من حيث الثكل الخارجي Morphology للمستعمرات وتعددية الاشكال. ويتفق مع ما ذكره (Sugumaran, 2013 Wu et al., 2012; Gaur and Singh, 2010; مول نعددية الاشكال

. A. pullulans التي يتميز بها الفطر ملنره

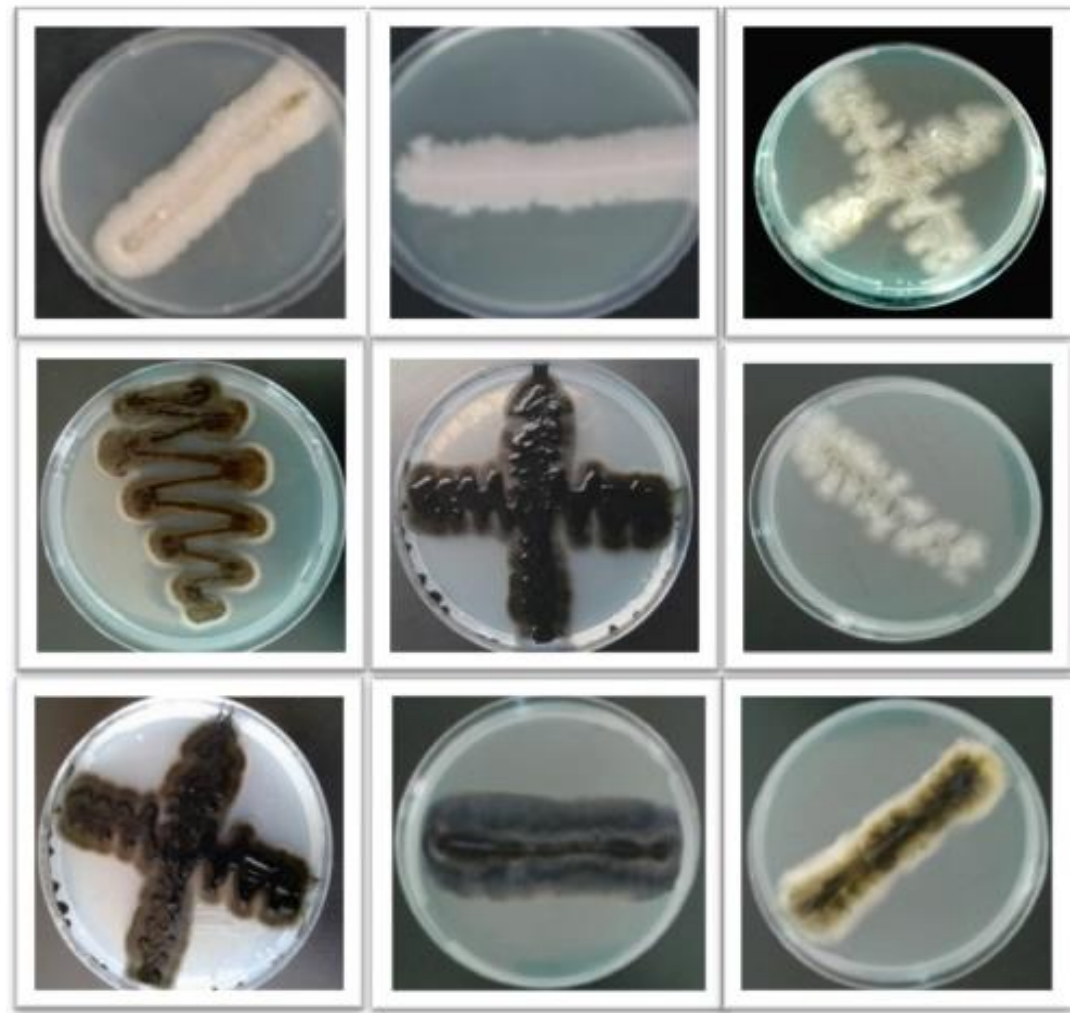

A. pullulans الثكل 1: الثكل المظهري لمزارع العزلات المحلية للفطر
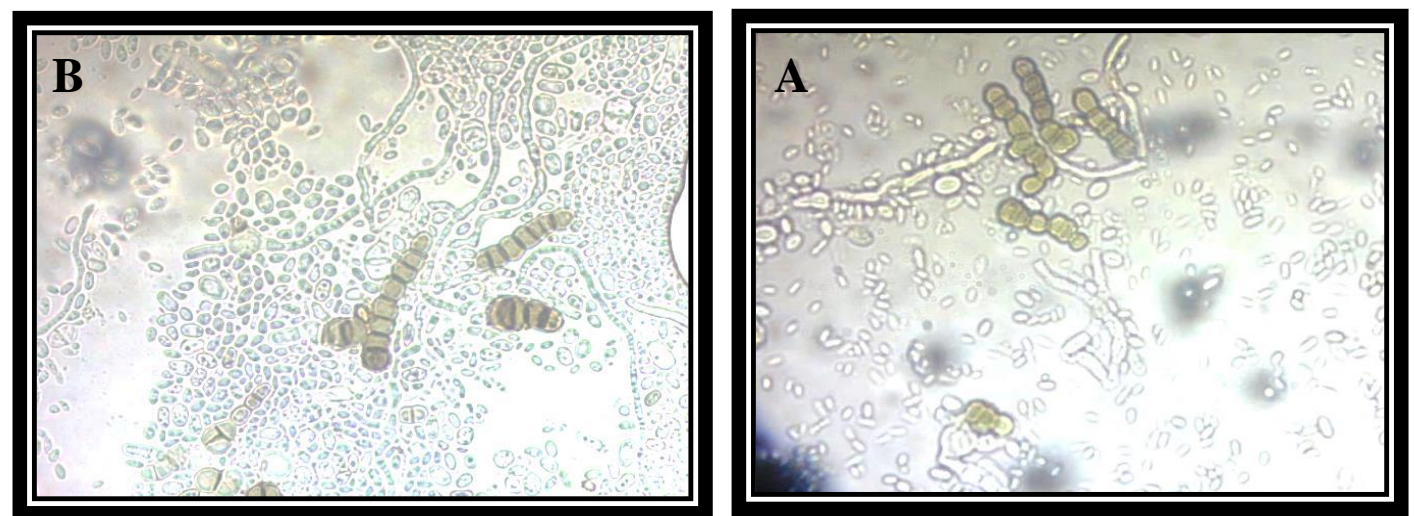

الثكل 2: A A الععدد الاثكال المظهرية للفطر A. pullulans العزلة المحلية

A. pullulan NRRL58560 العينة القياسية للفظر الفظة -B

عزل الـ DNA الـ 
بعد عزل الـDNA الجينومي للعزلات المحلية من الفطر A.pullulans و إجراء الترحيل الكهربائي لعينات الـ المنقاة باستخدام هلام الـ Agarose بتركيز 0.7\% نم تعريض الهلام للأشعة فوق البنفسجية عند الطول الموجي

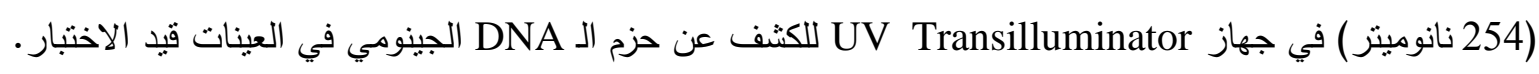

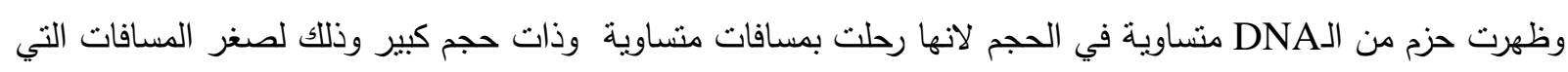

قطعتها في هلام الاكاروز لجميع عينات الـ DNA الجينومي المنقاة من العزلات الفطرية المحلية.

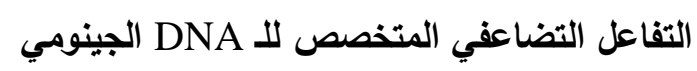
اجري التفاعل التضاعفي المتخصص لعينات الـ DNA المنقاة من العزلات المحلية باستخدام ITS4 revers (Hammo, 2013) ('TCCTCCGCTTATTGATATGC3') ومن الثكل (3) لوحظت 17 حزمة من الـDNA المنقى من العزلات الفطرية المحلية بحجم واحد يتراوح مابين (500-

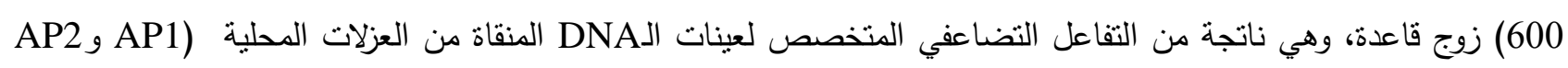

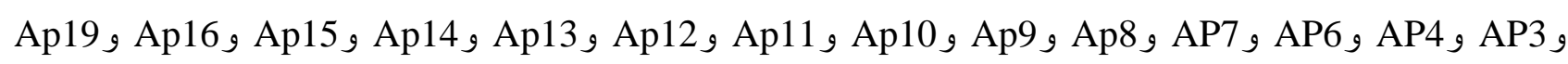

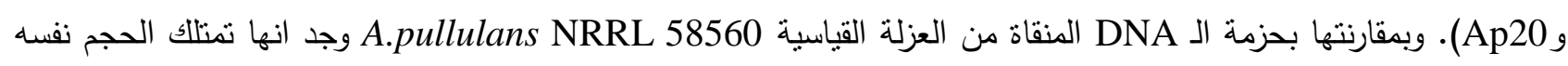

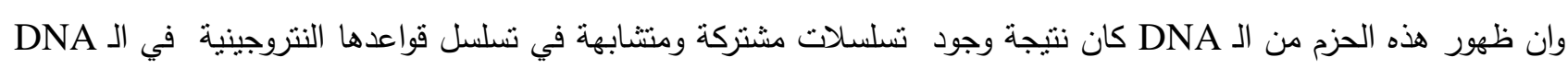

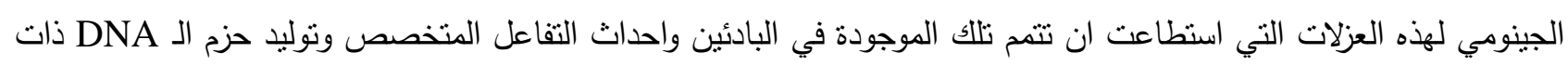
الاحجام المتشابهة.

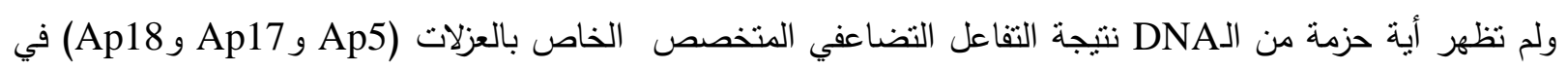
هلام الاكاروز • وربما يعود ذلك الى فثل ارتباط الـDNA القالب بالبادئ، أو الى عدم وجود تسلسلات من القواعد النيتروجينية في الـDNA الجينومي لهذه العزلات التي لها امكانية ارتباطها بالبادئ. ان هذه النتائج التي تم الحصول عليها تتفق مع ما توصل إليه (2009) Martini et al., عند استخدامه تقنية التفاعل التضاعفي المتخصص لتوصيف عينات الـ DNA الجينومي المنقاة من عزلات الفطر A.pullulans وكان حجمها يتراوح مابين (500-600) زوج قاعدة باستخدام البادئ ITS1 و Alam et al. وكن (2009) باستخدام ثقنبة التفاعل التضاعفي المتخصص من نتخيص 9 عزلات محلية من الفطر من التفاعل يتراوح بين (575-625) زوج قاعدة.

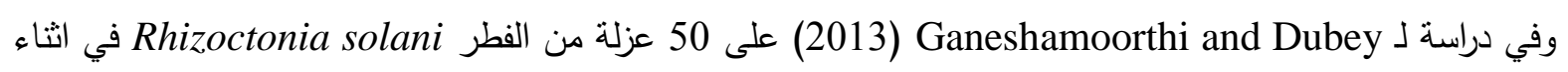
التفاعل التضاعفي المتخصص باستخدام البادئات ITS1 و ITS4 ظهرت حزم من الـ DNA بحجم واحد لجميع العزلات بلغ عددها (650) زوج قاعدة. 


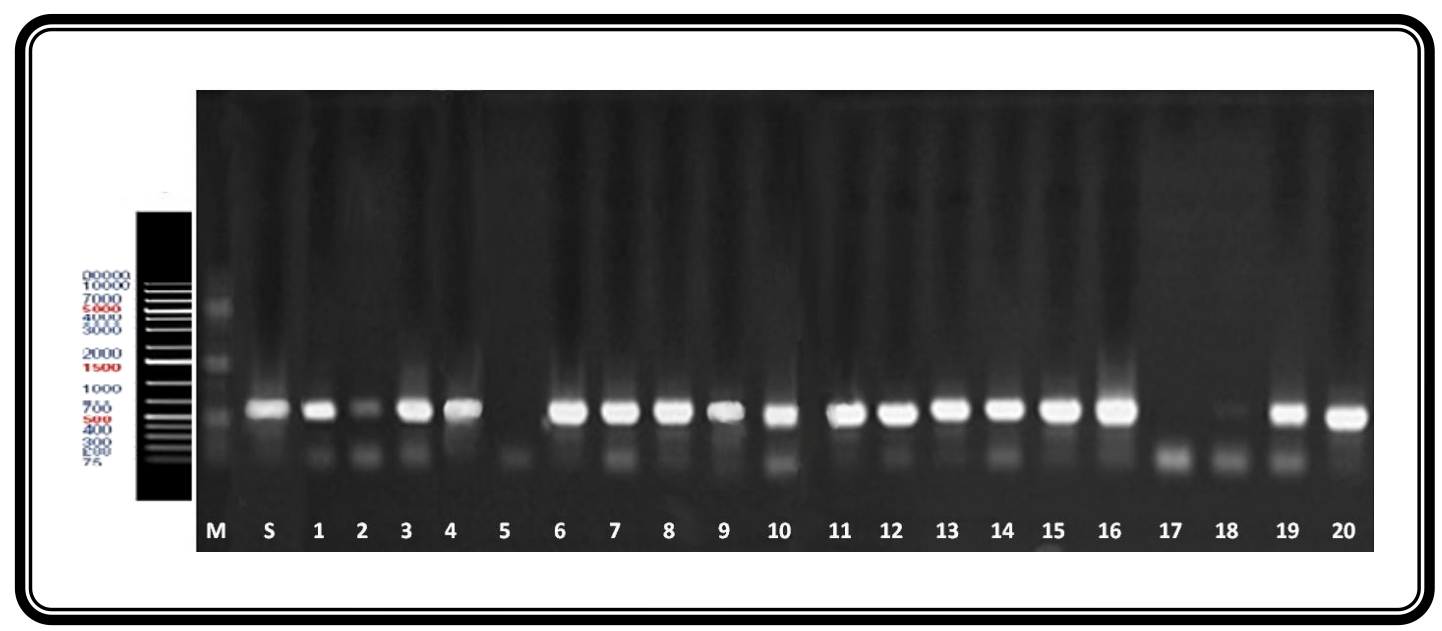

الثكل 3: نتائج التفاعل التضاعفي المتخصص للعزلات الفطرية المحلية
A. pullulans
A. pullulans NRRL58560 العزلة القياسية 3: نانية (S)

Marker \#SM1331 Gene Ruler Fermentas (M)

Specific PCR دراسة وتحليل تسلسل القواعد النايتروجينية لنواتج التفاعل التضاعفي المتخصص الـ أخذت نواتج التفاعل التضاعفي المتخصص Specific PCR لعينات الـ DNA الـ المنقاة من ثلاث عزلات محلية التي اختيرت من بين 17 عزلة اعطت نتيجة موجبة في تفاعل PCR وهي العزلات Ap1 و Ap7 و Ap14 وارسلت الى مركز الجينوم/ كلية العلوم والصحة/ جامعة كويا لإجراء عملية الـ Sequencing عليها. حيث نم الحصول على تسلسلات من القواعد النايتروجينية لعينات الـDNA.

ادخلت هذه التسلسلات في برنامج تحليل DNA BLAST عن طريق الريط الالكتروني: التهاء http://blast.ncbi.nlm.nih.gov/Blast.cgi والمسجلة في بنك الجينات Gene Bank اذ اظهرت نتائج التحليل وجود نتابه كبير بنسبة 98\% بين نسلسلات العزلة Ap1 وتسلسلات العزلة الفطرية Aureobasidum pullulans المسجلة في بنك الجينات بالرقم KC253972.1 (الثكل 4 و 5).

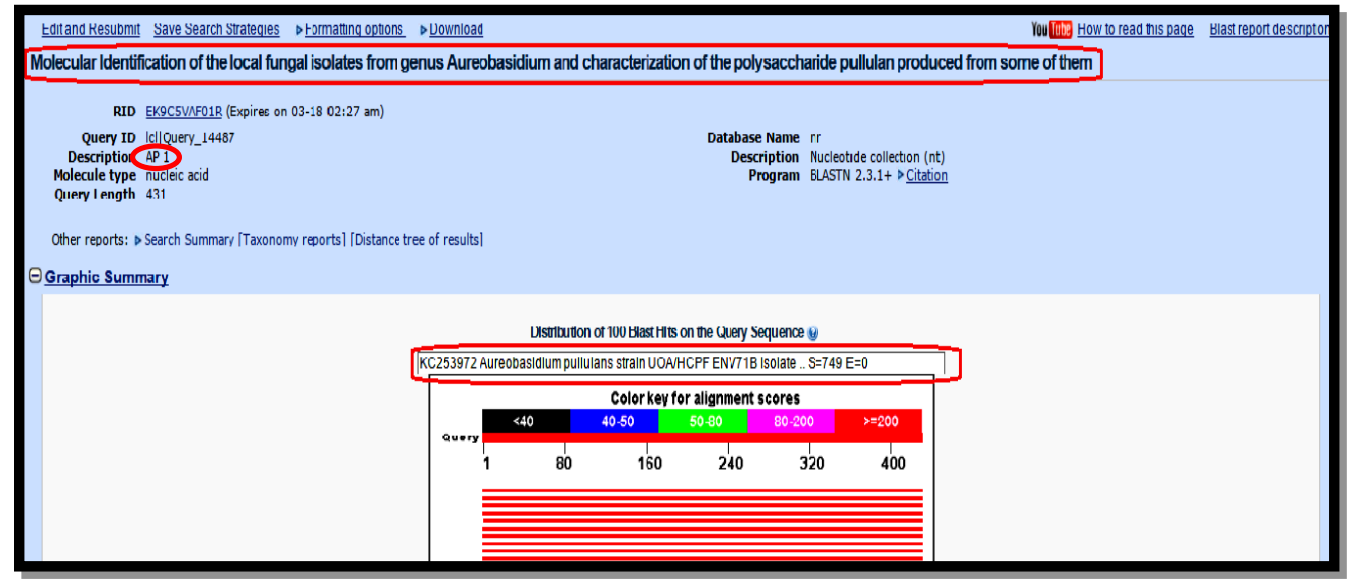

الثكل 4: برنامج التحليل لتسلسلات القواعد النايتروجينية للعزلة الفطرية المحلية ANA BLAST/NCBI Ap1

Aureobasidium pullulans strain UOA/HCPF ENV71B isolate ISHAM-ITS_ID MITS391 18 S ribosomal RNA gene, partial sequence; internal transcribed spacer $1,5.8 \mathrm{~S}$ ribosomal RNA gene, and internal transcribed spacer 2, complete sequence; and 26S ribosomal RNA gene, partial sequence. Sequence ID: gb|KC253972.1|Length: 577Number 


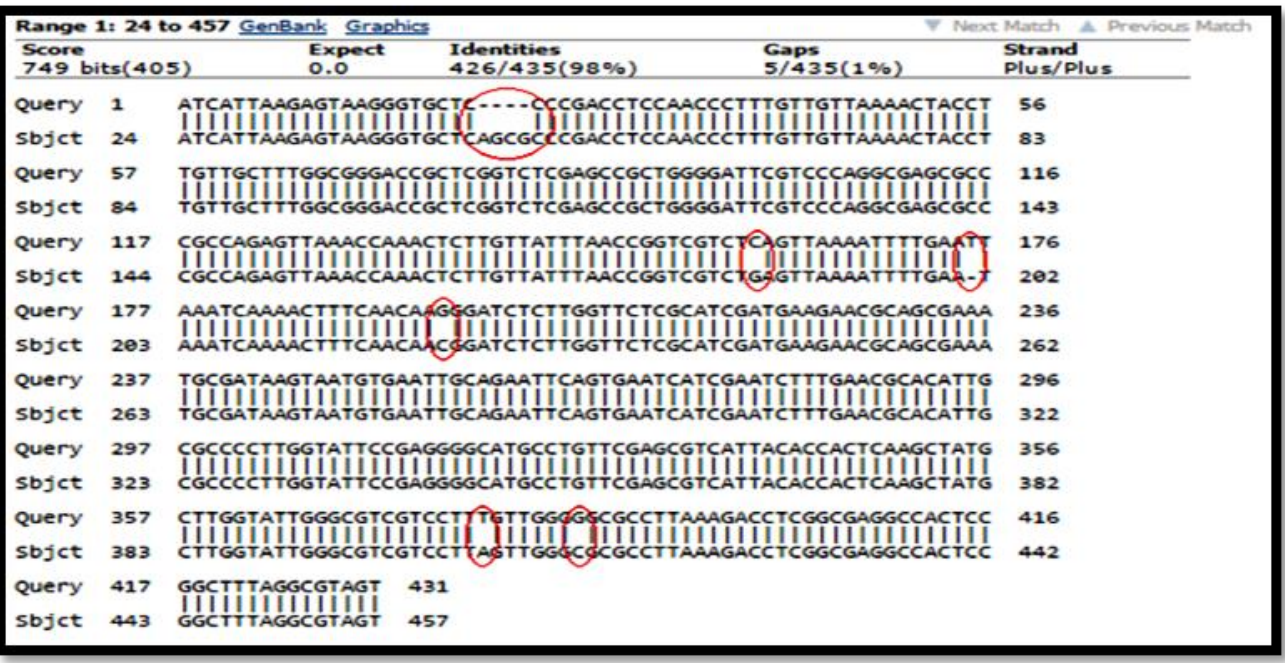

الثكل 5: مقارنة تسلسلات القواعد النايتروجينية بين العزلة المحلية Ap1 والسلالة القياسية المسجلة بالرقم gb|KC253972.1|

كما أظهرت نتائج التحليل باستخدام برنامج DNA BLAST وجود نشابهاً بنسبة 98\% بين نسلسلات العزلة AP 7 مع تسلسلات السلالة الفطرية Aureobasidium والمسجلة في بنك الجينات بالرقم KU671017.1 اذ كانت اغلب التسلسلات منشابهة الى حد كبير (الثكل 6 و 7).

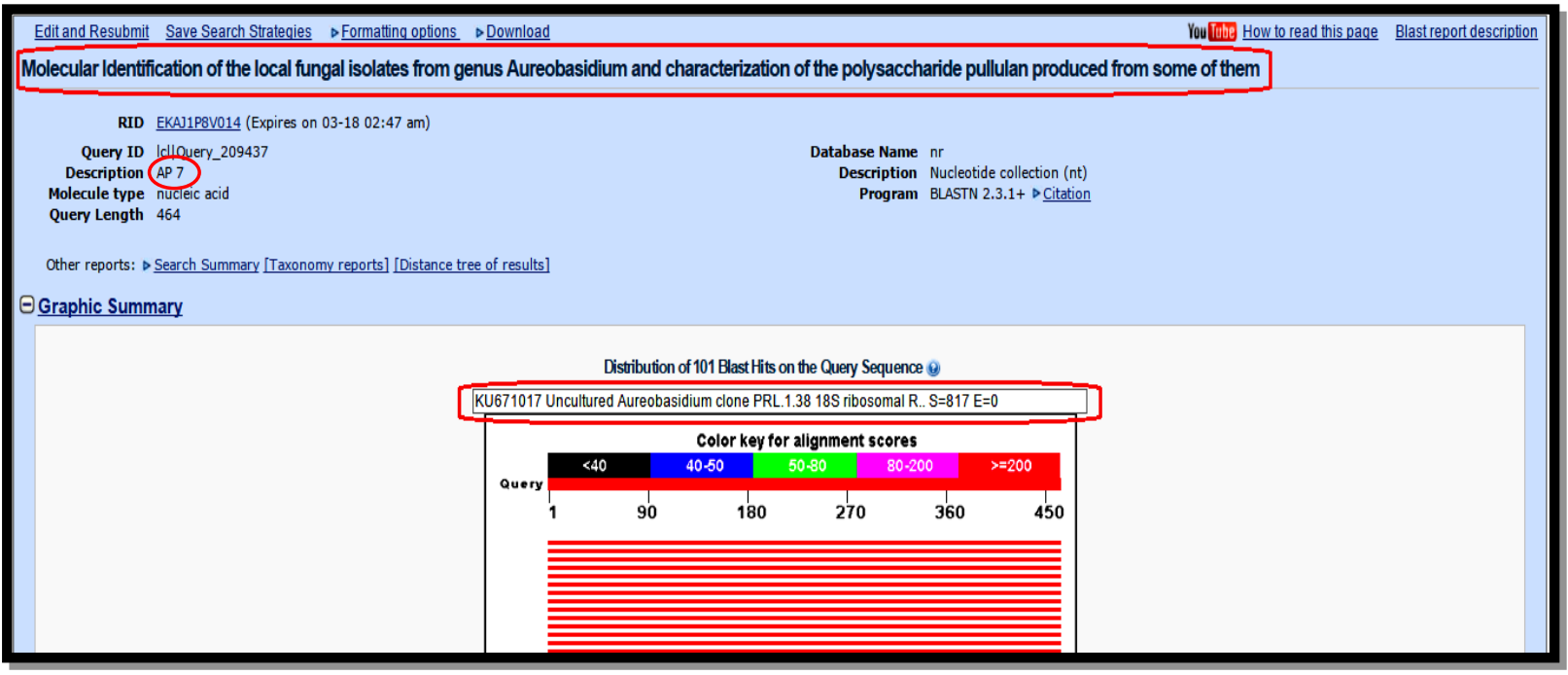

DNA BLAST/NCBI Ap7 الثكل 6: نتائج برنامج التحليل لتسلسلات القواعد النايتروجينية للعزلة الفطرية المحلية Uncultured Aureobasidium clone PRL.1.38 18S ribosomal RNA gene, partial sequence; internal transcribed spacer 1, 5.8S ribosomal RNA gene, and internal transcribed spacer 2, complete sequence; and 28S ribosomal RNA gene, partial sequence GenBank: KU671017.1 Length: 542 Number 


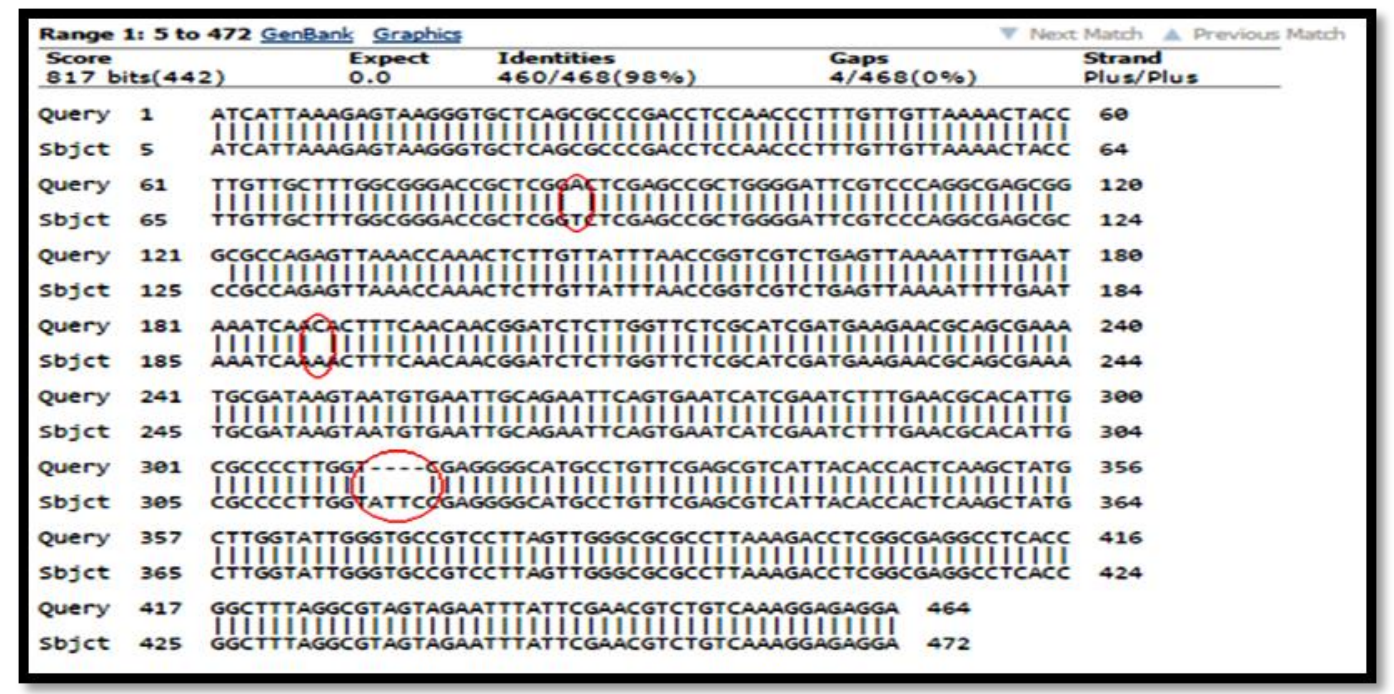

الثكل 7: مقارنة تسلسلات القواعد النايتروجينية بين العزلة المحية Ap7 والسلالة القياسية المسجلة بالرقم

كذلك أظهرت نتائج التحليل باستخدام برنامج DNA BLAST وجود تشابهاً بنسبة 99\% (الجدول 1) بين تسلسلات العزلة Ap14 وتسلسلات السلالة A. pullulans والمسجلة في بنك الجينات بالرقم

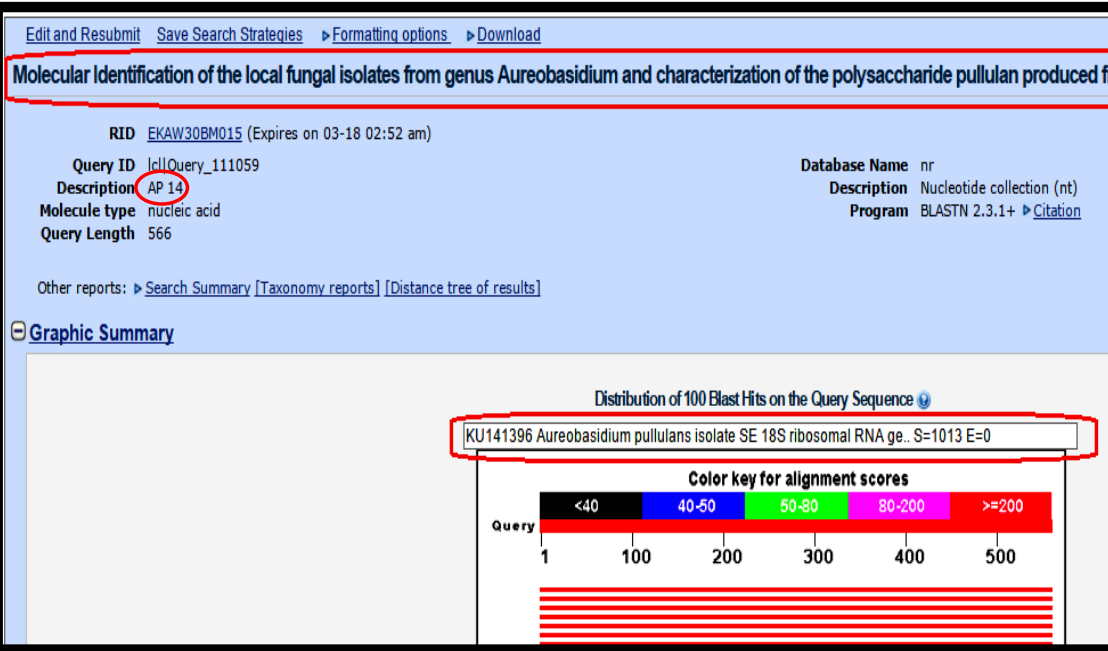

الثكل 8: نتائج برنامج تحليل تسلسلات القواعد النايتروجينية للعزلة الفطرية المحلية Ap14

Aureobasidium pullulans isolate SE $18 \mathrm{~S}$ ribosomal RNA gene, partial sequence; internal transcribed spacer 1, 5.8S ribosomal RNA gene, and internal transcribed spacer 2, complete sequence; and 28S ribosomal RNA gene, partial sequence GenBank: KU141396.1 Length: 600 Number 


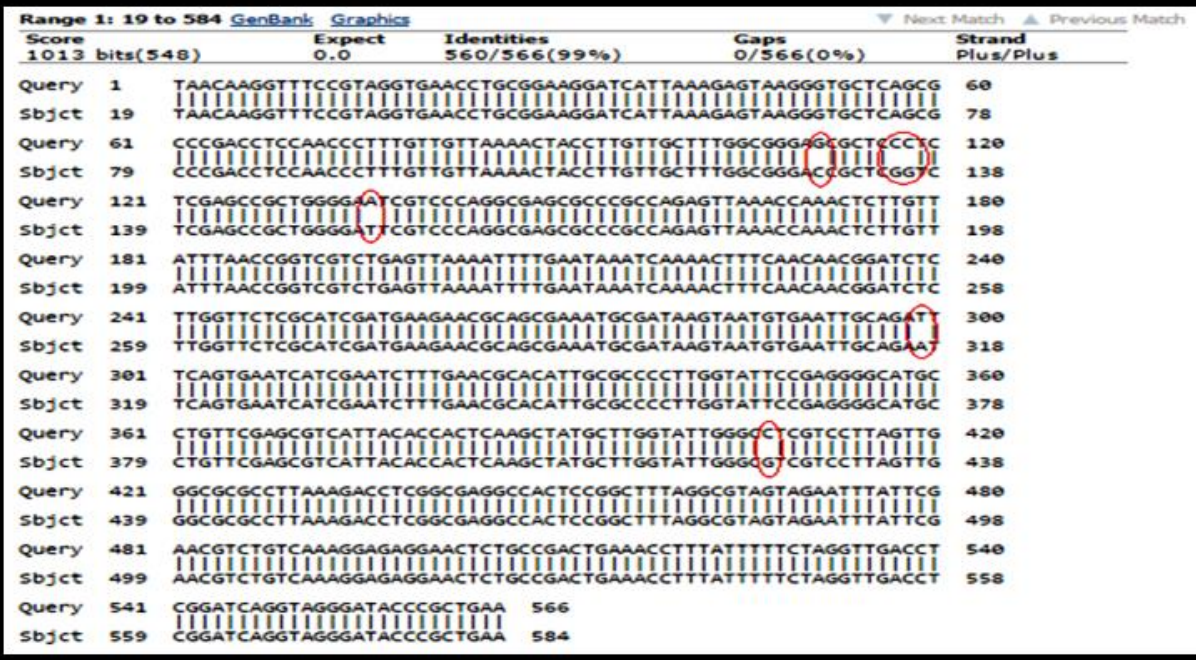

الثكل 9: مقارنة تسلسلات القواعد النايتروجينية بين العزلة الفطرية المحلية Ap14 والسلالة القياسية المسجلة بالرقم KU141396.1

كما لوحظ من نتائج التحليل اختلاف في بعض القواعد النايتروجينية بين العزلات المحلية والسلالات القياسية المشابهة لها من بنك الجينات في بعض المواقع عند مقارنة التسلسلات العائدة للعزلات المحلية وتلك القياسية، وهذا الاختلاف يمثل طفرات نقطية Point Mutations حدثت على مستوى تسلسلات الـ DNA للعزلات الفطرية والتي تشمل استبدال قاعدة باخرى في تسلسل القواعد النايتروجينية، او حذف قاعدة من التسلسل، او اضافة قاعدة الى التسلسل. ان طفرات الاستبدال التي حدثت هي طفرات

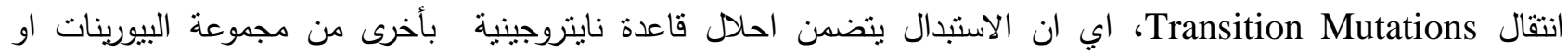
البيرميدينات نفسها. علما ان هذه الطفرات قد حدثت نلقائياً (الجدول 2).

الجدول 1: العزلات المشخصة لفطر Aureobasidium بالاعتماد على التسلسلات الموجودة في بنك الجينات

\begin{tabular}{|c|c|c|c|}
\hline رقم السلالات القياسية المحددة & التشبة & عدد القواعد & 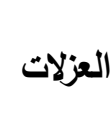 \\
\hline A. pullulans KC253972.1 & $\% 98$ & 431 & Ap1 \\
\hline Aureobasidium KU671017.1 & $\% 98$ & 464 & Ap7 \\
\hline A. pullulans KU141396.1 & $\% 99$ & 566 & Ap14 \\
\hline
\end{tabular}




\section{الجدول 2: التباين في مواقع القواعد النايتروجينية بين العزلات المحلية والسلالة القياسية المشابهة من بنك الجينات}

\begin{tabular}{|c|c|c|c|c|}
\hline \multirow{2}{*}{ موقع تسلسل القاعدة النايتروجينية } & \multicolumn{2}{|c|}{ والمطابقة لها النتروجينية للعزلات قيد الدراسة } & \multirow{2}{*}{ بنك الجينات القياسية المطابقة لها في } & \multirow[t]{2}{*}{ العزلة المحلية } \\
\hline & السلالة القياسية & العزلة المحلية & & \\
\hline 23 & $\mathrm{~A}$ & - & \multirow{9}{*}{ A.pullulans KC53972.1 } & \multirow{9}{*}{ Ap1 } \\
\hline 24 & $\mathrm{G}$ & - & & \\
\hline 25 & $\mathrm{C}$ & - & & \\
\hline 26 & $\mathrm{G}$ & - & & \\
\hline 15 & $\bar{G}$ & $\mathrm{C}$ & & \\
\hline 175 & - & $\mathrm{T}$ & & \\
\hline 196 & $\mathrm{C}$ & $\bar{G}$ & & \\
\hline 379 & $\mathrm{~A}$ & $\mathrm{~T}$ & & \\
\hline 386 & $\mathrm{C}$ & $\mathrm{G}$ & & \\
\hline 86 & $\mathrm{~T}$ & A & \multirow{7}{*}{$\begin{array}{r}\text { Aureobasidium } \\
\text { KU671017.1 }\end{array}$} & \multirow{7}{*}{ Ap7 } \\
\hline 121 & $\mathrm{C}$ & $\mathrm{G}$ & & \\
\hline 188 & A & $\mathrm{C}$ & & \\
\hline 312 & $\mathrm{~A}$ & - & & \\
\hline 313 & $\mathrm{~T}$ & - & & \\
\hline 314 & $\mathrm{~T}$ & - & & \\
\hline 315 & $\mathrm{C}$ & - & & \\
\hline 111 & $\mathrm{C}$ & $\mathrm{G}$ & \multirow{5}{*}{ A.pullulans KU141396.1 } & \multirow{5}{*}{ Ap14 } \\
\hline 117 & $\mathrm{G}$ & $\mathrm{C}$ & & \\
\hline 118 & $\mathrm{G}$ & $\mathrm{C}$ & & \\
\hline 136 & $\mathrm{~T}$ & $\mathrm{~A}$ & & \\
\hline 407 & $\mathrm{G}$ & $\mathrm{C}$ & & \\
\hline
\end{tabular}

وأدخلت تسلسلات القواعد النيتروجينية التي حصل عليها من تقانة الـ Sequencing في برنامج MoleBlast بوساطة الرابط الاكتروني:http:/blast.ncbi.nlm.nih.gov/moleblast/moleblast.cgi ؛ للحصول على مخطط شجيري للنمط الوراثي يوضح العلاقة بين العزلات الفطرية قيد الدراسة والسلالات الموجودة والمسجلة في بنك الجينات (الثكل 10). وفي ضوء المخطط الثجيري للنمط الوراثي Phylogenetic Tree (الثكل 10) لوحظ ان العزلة الفطرية المحلية كانت قريبة الى السلالة الفطرية القياسية المسجلة في بنك الجينات Aureobasidium pullulans gb/KC253972.1 وقريبة من السلالة القياسية.A.pullulans gb/AJ244233.1 وكذلك مقاربة للسلالة القياسية pullulans gb/FJ150907.1 . أما العزلة الفطرية المحلية Ap7 فقد ظهرت أقرب إلى السلالة القياسية Aureobasidium gb/KU671015.1 من غيرها وقريبة من A. pullulans var. melanogenum وقريبة من السلالة القياسية Aureobasidium gb/KU671017.1 السلة القياسية

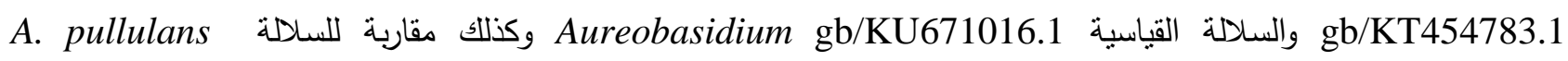
A. pullulans كانت اقرب إلى السلالة Ap Ap/KT352842.1 كما لوحظ أن العزلة الفطرية المحلية 14

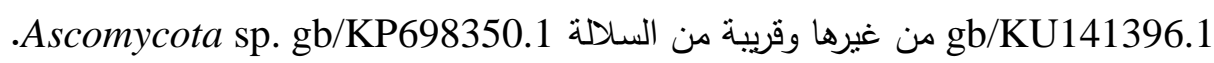




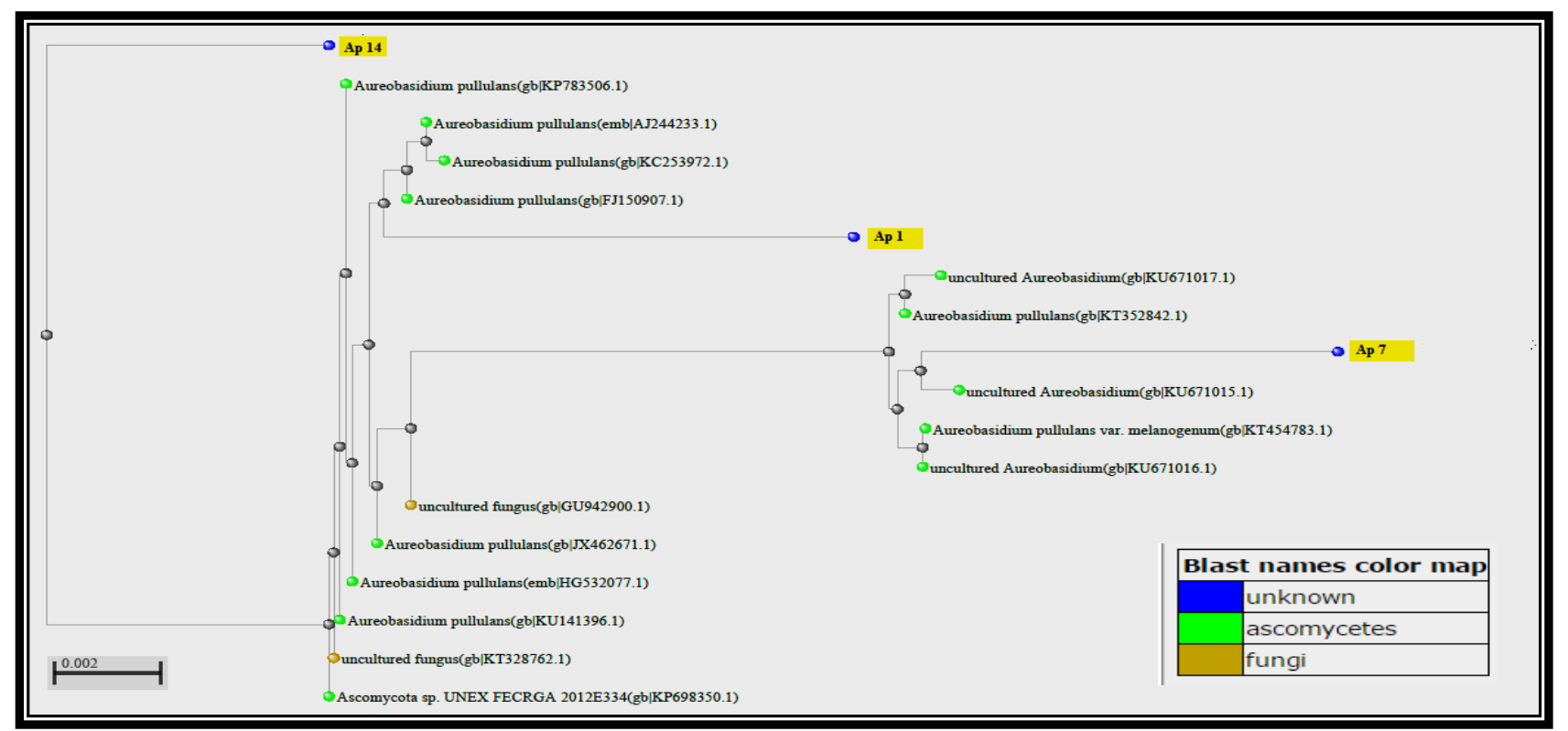

الشكل 10: المخطط الشجيري للنمط الوراثي لنتائج تحليل تسلسل القواعد النتروجينية لثلاثة عزلات محلية باستخدام

Mole-Blast

هذه النتائج تبين ان العزلات الفطرية المحلية تعود إلى الفطر A. pullulans وهذا ما يؤكد ويعزز النتائج التي تم

الحصول عليها من تقانة التفاعل التضاعفي المتخصص ويثبت صحة نتائج التشخيص التي نم الحصول عليها في هذه الدراسة. وتنفق هذه النتائج مع كثير من البحوث والدراسات، حيث استخدم الباحث (2005) Prasongsuk et al., تقانة لتشخيص عزلات الفطر Sequencing

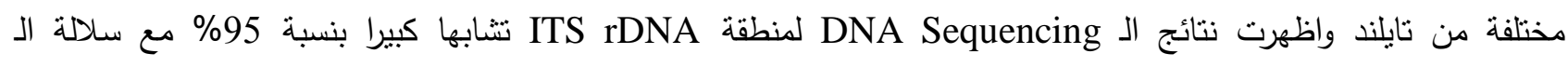
A.pullulans كما استخدم الباحث (2014) , Mirzwa-Mróz et al تقانة الـ DNA Sequencing في تشخيص 16 عزلة محلية من عزلات الفطر A. pullulans المعزولة من اشجار التفاح والعرموط المسببة لمرض التبقع الاسود، حيث تم الحصول

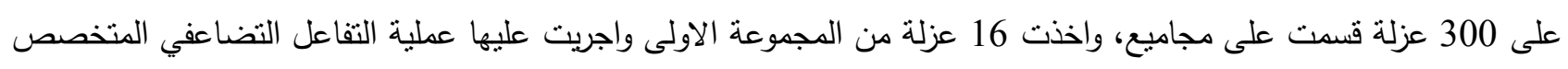

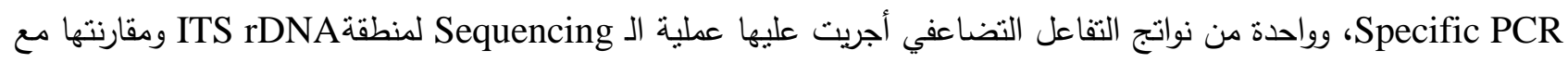
السلالات الموجودة في بنك الجينات واظهرت نتائج التحليل شبهها لـ A. pullulans بنسبة 100\% وتم مقارنة بقية العزلات مع نع هذه العزلة بالاعتماد على الصفات المظهرية. وتمكن Arzanlou (2014) من نشخيص 14 عزلة من الفطر .Aureobasidium المعزولة من الانسجة الوعائية

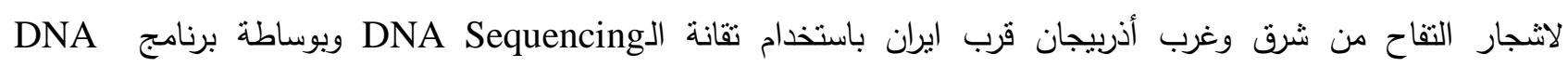
من خلال مقارنتها بالسلالات الموجودة في بنك الجينات اظهرت انها تعود لـ Alast/NCBI

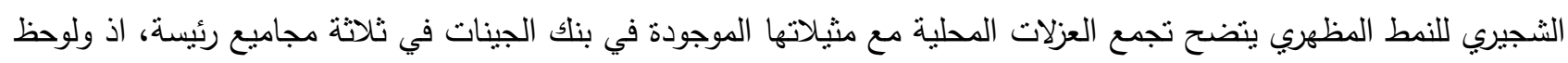
ان العزلات المحلية كانت منضوية تحت السلالة A. pullulans var. pullulans. 
وأوضح (Dovana et al., إمكانية إيجاد التباين الوراثي للعزلات الفطرية باستخدام تقانة الـDNA Sequencing. حيث تم عزل 19 عزلة من سيقان وجذور النباتات المائية كالMentha aquatica ودرست خصائصها المظهرية والنمو واجريت عملية الـ DNA Sequencing على منطقة ITS rDNA لإيجاد التباين الوراثي لـ 17 عزلة. واظهرت النتائج ان تسعة عزلات

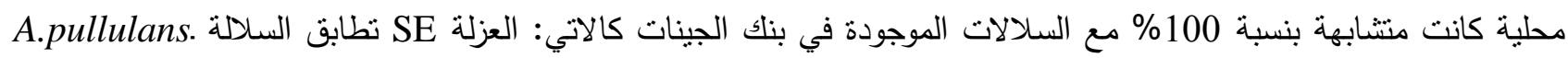
والعزلتين SA و SL تطابق ST2 Cadophora luteoolivacea نطابق ST2 , Cladosporium halotolerans

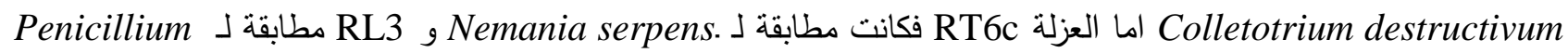
. Sarocladium strictum تطابق SS و RTenicillium solitum وكانت Resedanum وأرسلت نتائج التحليل هذه الى بنك الجينات باستخدام الموقع الاككتروني في الـ NCBI وادخلت في بنك الجينات كعزلة Ap7.sqn Ap7: Ap1.sqn Ap1 KX964610 قياسية واعطيت رقماً ورمزاً خاصاً بها في بنك الجينات كالاتي

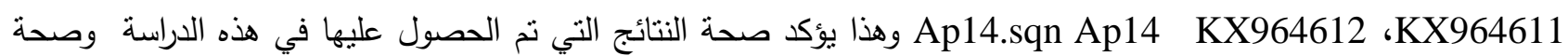

$$
\text { تشخيص العزلات المحلية قيد الدراسة. }
$$

\section{المصادر}

Alam, N.; Shim, M.J.; Lee, M.W.; Shin, P.G.; Yoo, Y.B.; Lee, T.S. (2009). Phylogenetic relationship in different commercial strains of Pleurotus nebrodensis based on ITS Sequence and RAPD. Mycobiol. 37 (3), 183-188.

Arzanlou, M. (2014). Molecular characterization of Aureobasidium species in Iran. Res. Mol. Med. 2(2), 28-33.

Dovana, F.; Mucciarelli, M.; Mascarello, M.; Fusconi, A. (2015). In vitro morphogenesis of Arabidopsis to search for novel endophytic fungi modulating plant growth. Plos One. J. Pone. 10(12), 1-18.

Dunber, J.; Ticknor, L.O.; Kuske, C.R. (2001). Phylogenetic specificity and reproducibility and new method for analysis of terminal resitriction fragment profiles of 16S rRNA genes from bacterial communities. Appl. Environ. Microbial. 67(1), 190-197.

Edwardes, I.P.; Turco, R.F. (2005). Inter-and intraspecific resolution of nrDNA TRFLP assessed by computer-simulated restriction analysis of a diverse collection of ectomycorrhizal Fungi. Mycol. Res. 109(2), 212-226.

Ganeshamoorthi, P.; Dubey, S.C. (2013). Anastomosis grouping and genetic diversity analysis of Rhizoctonia solani isolates causing wet root rot in chickpea. African J. Biotechnol. 12(43). 6159-6169.

Gaur, R.; Singh, R. (2010). Optimization of physic- Chemical and Nutritional parameters for pullulan production by amutant of Thermotolerant Aureobasidium pullulans in Fed batch Fermentation process. African J. Biotechnol. 9(43), 7322-7330.

Hammo, B.Y. (2013). Diagnostic and molecular genetic study for yeast of genus Saccharomyces isolated from different sources in Mosul City. Ph. D. Thesis. Col. Edu. Un. Mousl. Iraq.

Hawkes, M.; Rennie, R.; Sand, C.; Vaudry, W. (2005). Aureobasidium pullulans infection: Fungemia in an infant and a review of human cases. Diag. Microbiol. Infect. Dis., 51, 209 213

Leathers, T.D. (2003). Biotechnological production and applications of pullulan. Appl. Microbiol. Biotechnol. 62, 468-473.

Manitchotpisit, P.; Price, N.P.J.; Leathers, T.D.; Punnapayak, H. (2011). Heavy oils produced by Aureobasidium pullulans. Biotechnol. Lett. 33, 1151-1157.

Martini, M.; Musetti, R.; Grisan, S.; Polizzotto, R.; Borselli, S.; Pavan, F.; Osler. R. (2009). DNADependent detection of the grapevine fungal endophytes Aureobasidium pullulans and Epicoccum nigrum. Plant Dis. 93(10), 993-998. 
Mirzwa-Mróz, E.; Winska-Krysiak, M.; Dziciol, R.; Miękus, A. (2014). Characteristics of Aureobasidium pullulans (de Bary et Löwenthal G. Arnaud isolated from apples and pears with symptoms of sooty blotch in Poland. Acta. Sci. Pol., Hortorum Cultus. 13(3),13-22.

Ono, K.; Yasuha, N.; Ueda, S. (1977). Effect of $\mathrm{pH}$ on pullulan elaboration by Aureobasidium pullulans S. I. Agric. Biol. Chem., 41, 2113-2118.

Paolella, P. (1998). "Introduction to Molecular Biology". The McGraw-Hill Companies. Inc. U.S.A. 60-62.

Perez, R.I.; Chacón, J.; Fidalgo, A.; Martin, J.; Paraiso, V.; Muñoz-Bellido, J.L. (1997). Peritonitis by Aureobasidium pullulans in continuous ambulatory peritoneal dialysis. Nephorol Dial Transplant, 12, 1544-1545.

Pollock, T.J.; Thorne, L.; Armentrout, W.R. (1992). Isolation of new Aureobasidium strains that produce high-molecular- weight pullulans with reduced pigmentation. Appl. Environ. Microbiol. 58, 877-883.

Prasongsuk, S.; Sullivan, R.F.; Kuhirun, M.; Eveleigh, D.E.; Punnapayak, H. (2005). Thailand habitats as sources of pullulan- producing strains of Aureobasidium pullulans. J. Microbiol. Biotechnol., 21, 393-398.

Punnapayak, H.; Sudhadham, M.; Prasongsuk, S.; Pichayangkura, S. (2003). Characterization of Aureobasidium pullulans isolated from airborne spores in thailand. J. Indu. Microbiol.and Biotechnol., 30, 89-94.

Ray, M.J.; Dickinson, D.J.; Buck, M. (2004). Aureobasidium or Hormonema A Genetic Approach. The Inter. Res. Group on Wood Preservation. Paper Prepared for the $35^{\text {th }}$ Annual Meeting.

Sugumaran, K. R.; Gowthami, E.; Swathi, B.; Elakkiya, S.; Sirvastava, S.N.; Raavikumar, R.; Gowdhaman, D.; Ponnusami, V. (2013). Production of pullulan by Aureobasidium pullulans from Asian Palm. Kemel: Anovel Substrate. Carbohydr Polymer. 92, 697-703.

White, T. J.; Bruns, T.; Lee, S.; Taylor, J.W. (1990). "Amplification and Direct Sequencing of Fungal Ribosomal RNA Genes for Phylogenetics. In: PCR Protocols: A Guide to Methods and Apple". Academ. Press. Inc., New York. pp. 315-322.

Wu, S.; Chen, J.; Pan, S. (2012). Optimization of fermentation conditions for the production of pullulan by a new strain of Aureobasidiumpullulans isolated from sea mud and its characterization. Carbohydr.Polymer. 87, 1696-1700.

Yurlova, N.A.; de Hoog, G.S. (1997). A new variety of Aureobasidium pullulans characterized by exopolysaccharide structure, nutritional physiology and molecular features. Antonie. Van. Leeuwenhoek. 72,141-147. 